\title{
Lean Sigma Application for Bridge Improvement Project
}

\author{
Prayogi Purnapandhega, Akbar Adhiutama \\ School of Business and Management, \\ Bandung Institute of Technology \\ Bandung, Indonesia \\ prayogi.purna@sbm-itb.ac.id
}

\begin{abstract}
PT. XYZ operates 90 fields in Sumatra with two major fields, Duri and Minas. Duri field consists of 13 areas that are linked by the bridge. Therefore, the bridge has an important infrastructure in maintaining our operational and mobilization in Duri field. There were 96 damaged bridges (66 bridges in fair condition and 30 bridges in poor condition) should be repaired quickly. However, from baseline data of bridge's project construction during 2014-2015, it took 159 day in average to repair a bridge and there were only 4 bridges able to be completed construction through a year. This condition was very disrupted operation \& maintenance activities in Duri field. Lean Sigma as a tool for process improvement for all its worldwide operation, and that includes PT. XYZ. Lean Sigma Approach uses five steps namely Define, Measure, Analyze, Improve and Control. In this thesis, Lean Sigma will identify anything with potential value (both direct and indirect to project cost), with the ultimate goal of accelerating cycle time, less costs and with much fewer defects, compared with traditional business systems. The objective of Lean Sigma application in this final research is to improve process of delivering next bridges project with effective schedule, efficient cost and meet the quality requirement.
\end{abstract}

Keywords-Lean Six Sigma; DMAIC; Bridge Project; Project Management; Decision Making; Current Reality Tree; Value Focused Thinking.

\section{INTRODUCTION}

PT. XYZ operates 90 fields in Sumatra with two major fields, Duri-the world's largest steam flood development and Minas - the largest oilfield discovered in Southeast Asia. Additionally XYZ manages Dumai Wharf, the final terminal for oil transport. The majority of XYZ's Sumatra production came from fields in the Rokan Production Sharing Contract (PSC). Duri, the largest field, has been using steam flooding technology to improve production since 1985 and steam injection was deployed in 80 percent of the field since 2011.

Bridge is a transportation link lines between areas. In XYZ operation area, bridges are most often found in Duri field. The business issues in this thesis is high number of damaged bridge should be repair quickly. There are 30 bridges in poor condition and need to repair quickly. Those 30 bridges were blocked, so vehicle which want to pass it should find another route and it takes more long travelling time.

Duri field consists of 13 areas that are linked by a bridge. Therefore, the bridge has an important function in maintaining our operational and mobilization in Duri field. The majority of the bridges in Duri field were damaged, due to the affected of corrosion on its steel pile (foundation). The impact of this corrosion will affect to the bridge losing its strength support, so that it cannot carry vehicle load as the original design. It will cause hazards for vehicles $\&$ equipment which pass through the bridge. The road had closed due to bridge in damaged condition.

Business issue in this study is long period to repair a bridge. From baseline data of bridge's project construction during 2014-2015 as seen on figure 4.,it took 159 day in average to repair a bridge that is resulting operation disrupted in Duri field. There are 4 bridges are only able to be completed construction within 1 year, while there were 96 damaged bridges ( 66 bridges in fair condition and 30 bridges in poor condition). This research will adopt Lean Six-Sigma study to solve the business issue.

\section{CONCEPTUAL FRAMEWORK}

Framework development of this study will be used to identify problems arises in capital projects that are executed in on-plot facilities where contractors start the work very late. The framework will help analyze on how do these happen and how to improve the process in order to increase contractor effective working hour per day by innovative construction method.

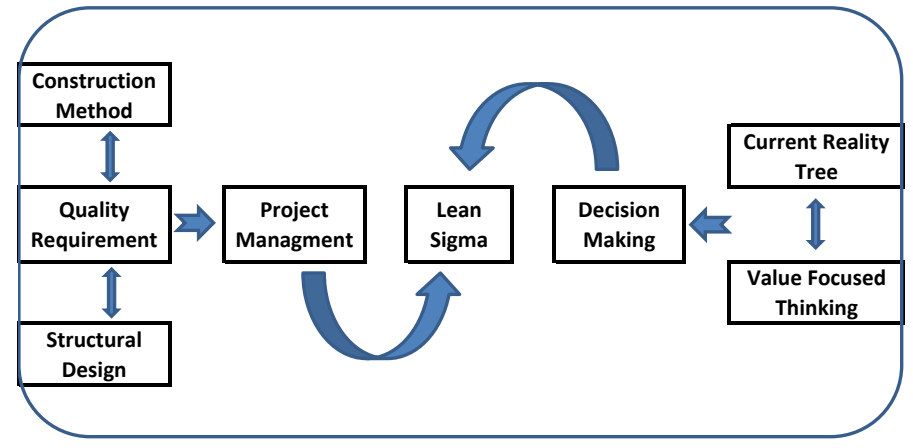

Figure 1. Bridge Project Conceptual Framework 
As seen on figure 1. the collaboration between project management and decision-making are tools to analyze problem and identify opportunity of Lean Sigma Project in this research. Project management are consist of construction method, quality requirement and structural design. Then, decision-making are using tools Current Reality Tree (CRT) and Value Focused Thinking (VFT).

\section{LITERATURE REVIEW}

Lean Sigma is from the combination of Lean Manufacturing and Six Sigma (SS); namely Lean Six Sigma is used. SS and Lean are proven improvement methodologies, and when these two are combined, the limitations of each methodology are expected to be overcome, resulting in enhanced customer satisfaction and improved bottom line results (Snee, 2010). In general terms, the term of Lean Six Sigma (LSS) has been used to describe the joint effort of SS and Lean (Sheridan, 2000).

Lean Six Sigma Approach uses five steps namely Define, Measure, Analyze, Improve and Control. Beside its proven frameworks to improve existing processes (Snee, 2005:38), this framework was chosen as an approach since XYZ has adopted Lean Six Sigma as a tool for process improvement for all its worldwide operation, and that includes PT.XYZ.

Lean will identify things that do not have additional value (waste), with the ultimate goal of accelerating cycle time. The methodology was originally developed by Toyota to identify the 8 waste in production processes. Eliminating waste along entire value streams, instead of at isolated points, creates processes that need less human effort, less space, less capital, and less time to make products and services at far less costs and with much fewer defects, compared with traditional business systems. Companies are able to respond to changing customer desires with high variety, high quality, low cost, and with very fast throughput times. In addition, information management becomes much simpler and more accurate.

\section{METHODOLOGY}

The methodology concept of business solution can be seen from flow diagram in figure 2 . below:

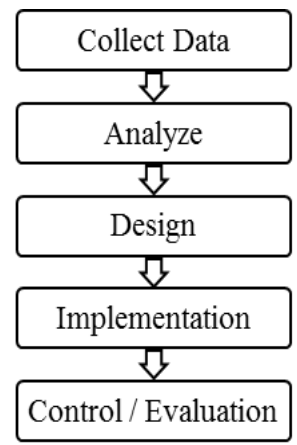

Figure 2. Research Method Flow Diagrams

\section{A. Collect Data}

Before start to research, data is an important information to know what to do. Collect data can be gathered from baseline data and voice of customer. Baseline data will be used as a benchmark, then voice of customer will be used as an expected goals.

\section{1) Baseline Data}

Based on past experience ( 4 previous project), the repair job for 1 bridge project took about 159 days and required cost to repair IDR 31,047,216.04 per $\mathrm{m}^{2}$ in average.

Refer to the operational needed, time construction should be completed quickly. Otherwise, the blocked road will hamper the operations which indirectly impact on production cycle. There is opportunity to improve the design and construction method to reduce cycle time of bridge repair job, which will have an impact on reducing the overall cost of construction works.

\section{2) Voice of Customer}

Voice of Customer capturing and analysis is a very important part of the product development process (Yang K, 2007). To collect the Voice of Customer, the writer (as well as the facilitator for the project) conducted interview with the Champion (Team Leader of Production Team in several area) during a meeting in January 2016. These voices then translated into Critical Customer Requirement (CCR). CCR is a translation data from the $\mathrm{VoC}$ into quantitative data and has several advantages:

- Specific and measurable

- Dealing directly with the product attributes

- Complete and unambiguous

- Describe what the customer wants and how to achieve it.

From the Customer Critical Requirement on table 3., we can conclude that it is desired for Special Project, Production team \& Contractor to get project on schedule, on budget and durable with consistent implementation of Safe Work Practices (a governing procedure that includes the permitting process).

\section{B. Analysis}

After data has been obtained, start to analyze the problem, find opportunity and provide several alternative design to solve the problem. Then analyze all the alternative design by considering cost, quality requirement, time duration.

\section{- Current Reality Tree (CRT)}

A CRT is a focusing procedure formulated by the late Eliyahu Goldratt, inventor of the theory of constraints. This process uses time-tested rules of logic to help leaders - in a few brief, but intensive sessions - gain a deep understanding about what really matters in any given situation. It treats multiple problems in a system as symptoms arising from one or a few ultimate root causes or systemic core problems. It describes, in a simple visual (cause-and-effect network) diagram, the main perceived symptoms (along with secondary or hidden ones that lead up to the perceived symptoms) of a problem scenario and ultimately the apparent root causes or core conflict. The benefit of building a CRT is that it is much easier to identify the connections or dependencies between 
perceived symptoms (effects) and root causes (core problems or conflicts). If core problems, for example in complex situations or crises, are identified, prioritized, and tackled well, multiple undesirable effects in the system will disappear (Dettmer, 1998).

From analysis, we can conclude that UDE (Undesirable Effect) are,

1) Require many scaffolding

2) Takes long time to construct

3) Slow delivery time of material

4) Complicated of preparation works

Both of problems above has identified the Core Problem is the bridge's project still using traditional design and details will be discussed on the next chapter. Traditional design means that bridges using middle pipe pile below bridge structure

\section{Design}

The best alternative design will be selected and developed. The selected design should be described in details and explained in working sequence.

\section{a) Value Focused Thinking}

Starting from fundamental objective, the alternatives and criteria are determining using Value-Focused Thinking (VFT) method. VFT is a method that describes the concepts and procedures for identifying opportunities and creating alternatives to solve decision problem (Ralph, 1996). Values are used as driving force for decision making.

Values determine the objectives of decision problem. The VFT method allows the following steps:

1) Identify fundamental objective considered for the decision context

2) Specify values (criteria) in order to measure objective performance

3) Recognize all possible alternatives/criteria that can achieve those objectives

4) Evaluate those alternatives/criteria

5) Select the best alternative/criteria

The most relevant and important criteria that influence the decision problem must be selected and provided to be used by VFT method for determining the best alternative. The following table 1 . shows the selected criteria.

Table 1. Alternative of Design

\begin{tabular}{|ll|}
\hline No & Alternative of Design \\
\hline $\mathbf{1}$ & Patching on Pipe Pile \\
\hline $\mathbf{2}$ & Re-Piling with similar design \\
\hline $\mathbf{3}$ & Replacing middle pile with bracing \\
\hline
\end{tabular}

a) Patching on Pipe Pile is a maintenance repair method using bigger diameter of existing pipe pile, then new material is patched by welding into corrosion spot.

b) Re-Piling with similar design as a traditional design because it is using the existing design (no design changed). c) Replacing middle pile with bracing is a new design by replacing middle pile with bracing, then install new pipe pile behind the wing wall, this design will make bridge has longer span than previous design.

Design comparison has already captured on table 2 .

Table 2. Design Comparison

\begin{tabular}{|l|c|c|c|}
\hline & Pipe Pile Patching & $\begin{array}{c}\text { Re-piling with } \\
\text { similar design }\end{array}$ & $\begin{array}{c}\text { Replace Middle } \\
\text { Pile with Bracing }\end{array}$ \\
\hline Life Service & 25 years & 50 years & 50 years \\
\hline Construction Cost & IDR 602,139,150 & IDR 1,664,192,655 & IDR 933,219,416 \\
\hline $\begin{array}{l}\text { Maintenance Cost } \\
\text { during 25 years }\end{array}$ & IDR 602,139,150 & - & - \\
\hline Total Cost & IDR 1,204,278,300 & IDR 1,664,192,655 & IDR 933,219,416 \\
\hline Delivery Time & 57 days & 159 days & 112 days \\
\hline $\begin{array}{l}\text { Delivery Time for } \\
\text { Maintenance }\end{array}$ & 57 days & - & - \\
\hline $\begin{array}{l}\text { Total Delivery } \\
\text { Time }\end{array}$ & $\mathbf{1 1 4}$ days & $\mathbf{1 5 9}$ days & $\mathbf{1 1 2}$ days \\
\hline
\end{tabular}

Design "Replace Middle Pile with Bracing" totally has the lowest cost and the fastest delivery time. Compare to another alternative, it has 50 years of life service and it does not need to maintain during it. So, The best design for Improve / repair broken bridge's steel pile in Duri field from benefit \& cost is Replace Middle Pile with Bracing.

\section{b) Bridge's Construction Method}

In new bridge design (Replace Middle Pile with Bracing) will improve construction method, re-route canal can be ignored and scaffolding work can be reduced. People not need to work above the river as in existing construction method.

The new construction has work sequence as follows:

1) Re-route canal (tentative, depend on existing wing wall condition)

- Re-route canal should be conducted If existing wing wall is need to be repaired.

2) Install scaffolding (tentative, install only for wing wall repairmen)

- Only install scaffolding if existing wing wall need to be repaired

3) Soil excavation

- Soil excavation in the bridge's abutment

4) Dismantle work

- Dismantle existing concrete slab, guardrail, and beam structure.

5) Install new structural work

- Install new pipe pile behind existing wing wall

- Fabricate more length of new frame structure

- Install guardrail

- Install concrete slab

6) Finishing

- Finishing is consist of painting, road treatment and housekeeping 


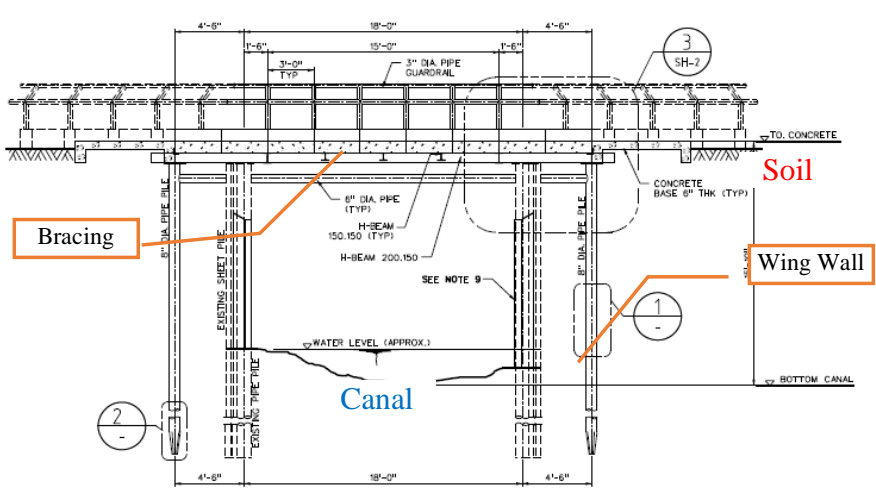

Figure 3. New Bridge's Design Drawing

From figure 3. show that new pipe pile will be installed behind the steel plate of wing wall and on the ground. Without scaffolding support, worker can be easily working on the ground to welding connected pipe pile into beam structure. With this new design, existing canal might not re-routed as previous process. Re-routed canal only will be conducted if wing wall need to be repaired.

To realize this method, the length of bridge should extend to the outside area of river. From the cost estimate, it is cheaper to extend the length of the bridge than using existing dimension while people is using scaffolding to work above the river.

\section{c) Material Selection}

The existing process as seen on figure 4 . is designing the bridges prior to checking material in warehouse. If material is unavailable, we should purchase new material and it takes 4 to 6 months to proceed until material on hand. This study has find out the opportunity to solve this material issue with new design process as seen on figure 5 . to avoid new material purchase.

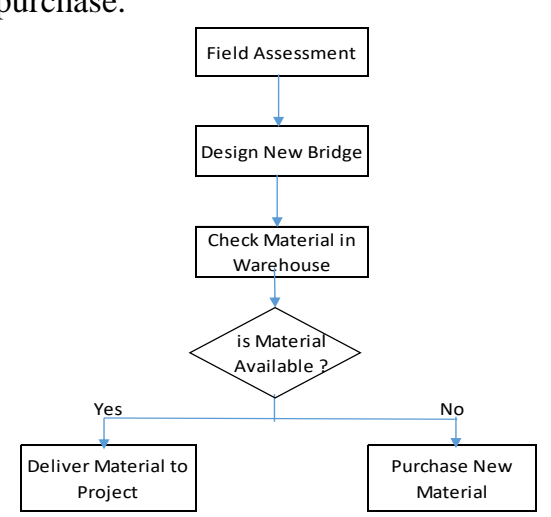

Figure 4. Existing Design Process

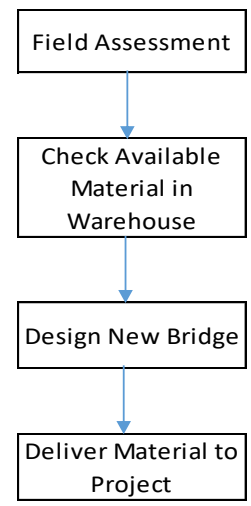

Figure 5. New Process

\section{Implementation}

After the selected design has been approved and clearly socialized to construction team and contractor, the next step is to implement / execute the project

\section{1) Project Description}

This project has been first implemented at bridge 7P22, PT. XYZ as owner, PT. Adhi Karya as contractor, Rekind Worley Parson as supervisor. This project was started on 9 January 2016 and finished on 16 April 2016.

\section{2) Project Activities}

Work sequence was documented on figure 6 . and will be describe as followed,

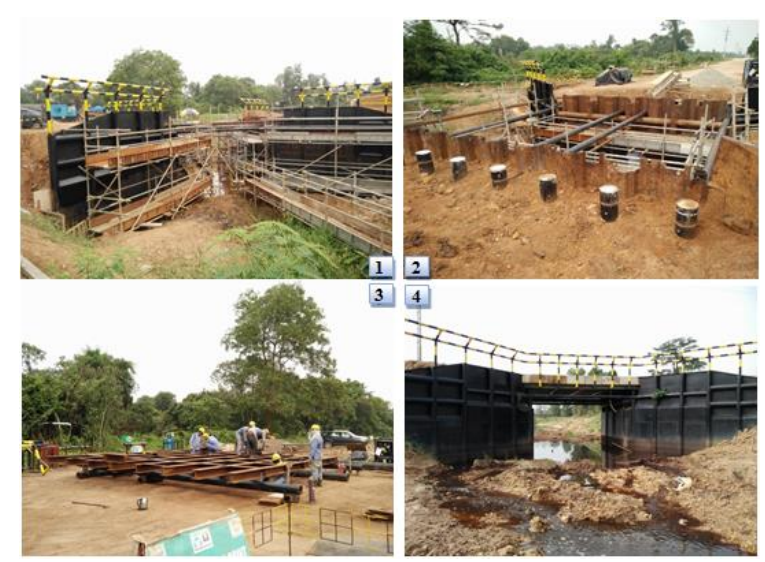

Figure 6. Photo Documentation at Bridge 7P22

Scaffolding is only be installed to repair existing wing wall. Then, New pipe pile is installed behind the wing wall to avoid directly contact with water canal (prevent major corrosion). This technique also make easily to weld connecting frame structure into pipe pile due to worker can easily to do it on the ground not on the scaffolding. Then after finished, new steel frame will be lifted, placed and connected to pipe pile. After all work sequence been complete, the bridge is ready in operation.

\section{E. Evaluation}

Evaluation is conducted after the project has been finished. Evaluation is intended to get lesson learned and opportunity to implement in the next project.

\section{1) Cycle Time}

Total Duration / repair cycle time has been obtained from completion date minus start date. Bridge 7P22 has 105 days of total project duration resulted the fastest repair cycle time compare to previous bridges as seen on table 3. and figure 7.

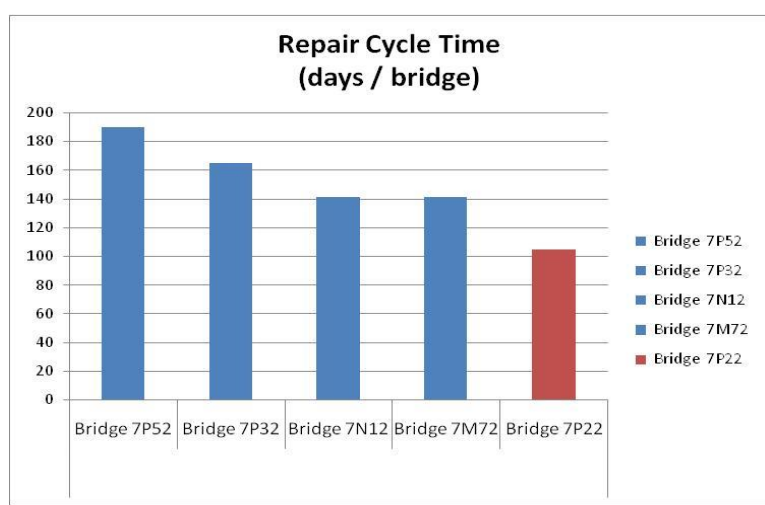

Figure 7. Chart of Bridge's Cycle Time Repair 
Table 3. Bridge's Cycle Time Repair

\begin{tabular}{|c|l|c|c|c|}
\hline & Location & Start Date & $\begin{array}{c}\text { Completion } \\
\text { Date }\end{array}$ & $\begin{array}{c}\text { Repair Cycle } \\
\text { Time } \\
\text { (days / bridge) }\end{array}$ \\
\hline \multirow{3}{*}{ Baseline Data } & Bridge 7P52 & 18-Aug-14 & 23-Feb-15 & 190 \\
\cline { 2 - 5 } & Bridge 7P32 & $15-$ Aug-14 & 26-Jan-15 & 165 \\
\cline { 2 - 5 } & Bridge 7N12 & 30-Jan-15 & 19-Jun-15 & 141 \\
\cline { 2 - 5 } $\begin{array}{c}\text { After } \\
\text { Improvement }\end{array}$ & Bridge 7M72 & 30-Jan-15 & 19-Jun-15 & 141 \\
\hline
\end{tabular}

\section{2) Financial Benefit}

Financial benefit has been calculated from material scaffolding requirement compared to bridge area which been constructed. Bridge 7P22 has IDR 17,281,841.04 of scaffolding cost per $\mathrm{m} 2$. If it compare to previous bridge that has been constructed, bridge 7P22 had succeed to save USD $50,983.04$ resulted the most efficient scaffolding cost compare to previous bridges as seen on table 4 . and figure 8 .

Table 4. Bridge's Scaffolding Cost

\begin{tabular}{|c|c|c|c|c|}
\hline & Location & $\begin{array}{c}\text { Bridge } \\
\text { Area (m2) }\end{array}$ & $\begin{array}{c}\text { Total Cost per } \\
\text { m2 (IDR) }\end{array}$ & $\begin{array}{c}\text { OPEX Saving } \\
\text { (IDR) }\end{array}$ \\
\hline \multirow{4}{*}{$\begin{array}{c}\text { Baseline } \\
\text { Data }\end{array}$} & Bridge 7P52 & 28.1 & $37,075,686.85$ & \\
\cline { 2 - 6 } & Bridge 7P32 & 39 & $28,418,048.72$ & \\
\cline { 2 - 6 } & Bridge 7N12 & 43.31 & $29,429,584.16$ & \\
\cline { 2 - 6 } & Bridge 7M72 & 43.31 & $29,265,724.43$ & \\
\cline { 2 - 6 } $\begin{array}{c}\text { After } \\
\text { Improverage } \\
\text { ment }\end{array}$ & Bridge 7P22 & $\mathbf{5 0}$ & $\mathbf{1 7 , 2 8 1 , 8 4 1 . 0 4}$ & $\mathbf{6 8 8 , 2 7 0 , 9 9 9 . 7 8}$ \\
\hline
\end{tabular}

\section{Total Cost per m2 (IDR)}

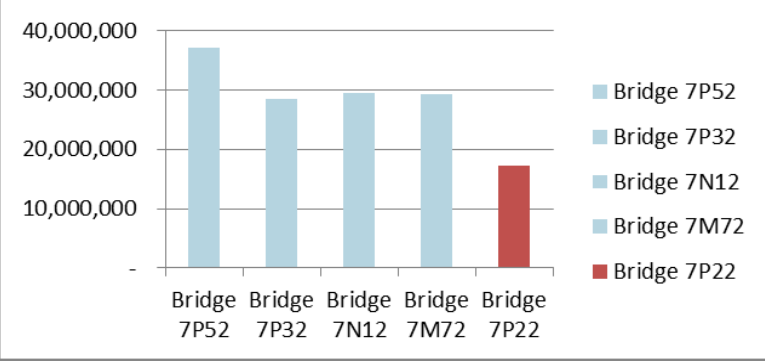

Figure 8. Chart of Bridge's Scaffolding Cost

\section{CONCLUSION}

The implementation of the Lean Six Sigma Project: "Bridge Improvement in Duri Field" was implementing successfully at bridge 7P22. In this research, we can conclude that the main root cause is traditional design and the solution is replacing it by new bridges design. So, new bridges design "Replace Middle Pile with Bracing" has successfully proven to reduce cycle time construction from 159 to 105 days, reduce totally cost of construction and successfully saving USD 50,983.04 per bridge and meet quality requirement (50 years of life service)

\section{REFERENCES}

[1] Ahuja, H, Dozzi, S, Abourizk, S 1994. Project Management Techniques in Planning and Controlling Construction Projects.Wiley, Second edition, pp. 2.

[2] Atkinson, R 1999. Project management: cost, time and quality, two best guesses and a phenomenon, its time to accept other success criteria. International Journal of Project Management Vol. 17, No. 6, pp. 337-342.

[3] Bloomberg. Crude Oil \& Natural Gas. viewed 20 January 2016, http://www.bloomberg.com/energy

[4] BSN, 2005.RSNI T-03-2005: Perencanaan stuktur baja untuk jembatan.

[5] Caltrans, February 2015. Bridge Design Practice, California Department of Transportation, Sacramento, CA.

[6] Dettmer, H 1997. Goldratt's Theory of Constraints: a systems approach to continuous improvement. ASQC Quality Press, pp. 62-119.

[7] Dettmer, H 1998. Breaking the constraints to world class performance. ASQ Quality Press, pp 69-102.

[8] George, M, Rowlands, D, Price, M, Maxey, J 2005. The Lean Six Sigma Pocket Tool Book. McGraw-Hill.

[9] Muralidharan, K 2015. Six Sigma for Organizational Excellence, pp 19-37.

[10] Ralph, L 1996.Value-Focused Thinking: Identifying Decision Opportunities and Creating Alternatives, Elsevier Science B.V.

[11] Sheridan, J 2000.Lean Sigma 'synergy'," Industry Week, vol. 249, no.17, pp. 81-82.

[12] Snee, R 2005. When Worlds Collide: Lean and Six Sigma, Quality Progress, vol. 38, no. 9, pp. 63.

[13] Snee, R 2010. Lean Six Sigma - getting better all the time, International Journal of Lean Six Sigma, vol. 1, no. 1, pp. 9-29.

[14] Yang K 2007. Voice of The Customer Capture and Analysis. McGraw-Hill. pp. 6-8. 